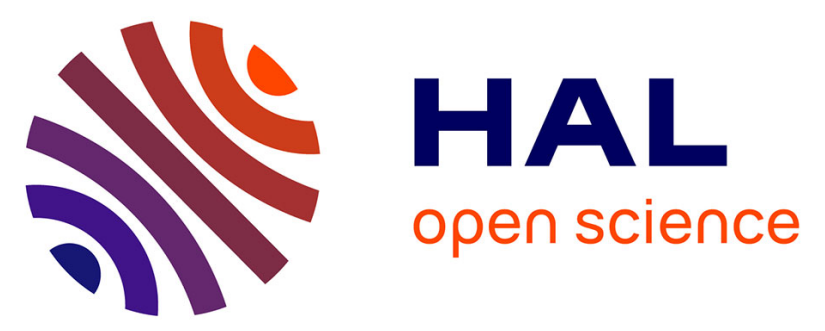

\title{
4x170 Gbit/s DWDM/OTDM transmission using only one quantum dash Fabry Perot mode-locked laser
}

Marcia Costa E Silva, Laurent Bramerie, Mathilde Gay, Sebastien Lobo, Michel Joindot, Jean-Claude Simon

\section{- To cite this version:}

Marcia Costa E Silva, Laurent Bramerie, Mathilde Gay, Sebastien Lobo, Michel Joindot, et al.. 4x170 Gbit/s DWDM/OTDM transmission using only one quantum dash Fabry Perot mode-locked laser. 36th European Conference on Optical Communication (ECOC 2010), Sep 2010, Torino, Italy. pp.We.6.C.2, 10.1109/ECOC.2010.5621270 . hal-00591826

\section{HAL Id: hal-00591826 https://hal.science/hal-00591826}

Submitted on 10 May 2011

HAL is a multi-disciplinary open access archive for the deposit and dissemination of scientific research documents, whether they are published or not. The documents may come from teaching and research institutions in France or abroad, or from public or private research centers.
L'archive ouverte pluridisciplinaire HAL, est destinée au dépôt et à la diffusion de documents scientifiques de niveau recherche, publiés ou non, émanant des établissements d'enseignement et de recherche français ou étrangers, des laboratoires publics ou privés. 


\title{
4×170 Gbit/s DWDM/OTDM Transmission using only one Quantum Dash Fabry Perot Mode-Locked Laser
}

\author{
M. Costa e Silva(1) ${ }^{(1)}$ L. Bramerie ${ }^{(1)}$, M. Gay ${ }^{(1)}$, S. Lobo ${ }^{(1)}$, M. Joindot ${ }^{(1)}$, J.C. Simon $^{(1)}$ \\ (1) Université Européenne de Bretagne (UEB), laboratoire Foton, CNRS/Université de Rennes 1 (UMR \\ 6082), Enssat, BP 80518, 22305 Lannion Cedex, France, Marcia.Costa-e-Silva@enssat.fr
}

\begin{abstract}
We demonstrate a $4 \times 170 \mathrm{Gbit} / \mathrm{s}$ DWDM/OTDM transmission experiment using only one quantum dash Fabry-Perot mode-locked laser. BER measurements show a penalty of $1 \mathrm{~dB}$ at $B E R=10^{-9}$ for back-to-back and error floor for $B E R=10^{-8}$ for transmission over $100 \mathrm{~km}$.
\end{abstract}

\section{Introduction}

The promising performance of semiconductor mode-locked laser diodes for many applications in telecommunications such as all-optical clock recovery ${ }^{1-4}$, high repetition rate source $^{5}$ or for access network applications ${ }^{6,7}$ has been already widely demonstrated. Quantum dot based active layers bring to this technology remarkable optoelectronic properties owing to the 3 dimensional carrier confinement leading mainly to a broad gain bandwidth and a low phase noise level. Taking advantage of these properties we already demonstrated the use of only one quantum dash Fabry-Perot modelocked laser as a tunable source for a 170Gbit/s transmission system ${ }^{8}$. This paper deals with a $4 \times 170 \mathrm{Gbit} / \mathrm{s}$ DWDM/OTDM transmission system with an efficiency of $0.42 \mathrm{bit} / \mathrm{s} / \mathrm{Hz}$, using this laser. Bit error rate (BER) measurements have been performed in back-to-back and transmission setup over $100 \mathrm{~km}$.

\section{4×170Gbit/s DWDM/OTDM source}

The quantum dash Fabry-Perot mode locked laser (QD-FP-MLLD) has been fabricated at III-V lab and already described in previous work ${ }^{3,5}$. Fig. 1 (a) depicts the wide and flat optical spectrum of QD-FP-MLLD. In a previous work we already showed the tuning capacity using a filter to select a channel and the individual performance of each channel has been characterized through BER measurements ${ }^{8}$. In this paper we propose to analyze the transmission of four channels simultaneously. Fig. 1 (b) illustrates the optical spectrum of this experiment and the numbers 1 to 4 refer to the four considered channels. Each of them was generated using a Gaussian filter with a $1.5 \mathrm{~nm}$ width at half maximum and blocked at $3 \mathrm{~nm}$ to avoid the interference between channels. The construction of these four channels uses a programmable shape optical filter that enables us to control the shape of the transfer function.

\section{$170 \mathrm{Gbit} / \mathrm{s}$ experimental setup}

The experimental set-up is shown in Fig. 2, which depicts the transmitter and receiver
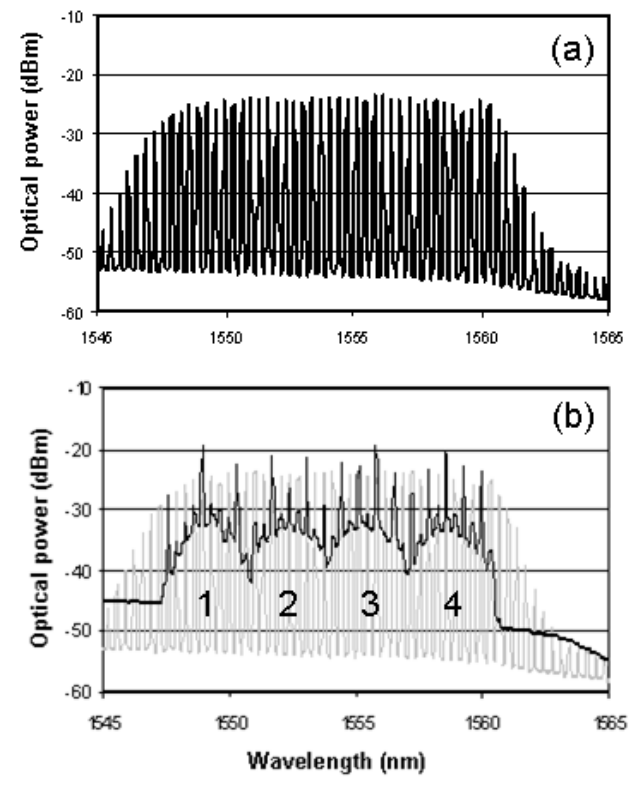

Fig. 1: Optical spectrum (a) QD-FP-MLLD (b) selection of four channels

blocks. In the transmitter block, the laser is actively mode-locked thanks to a standard $R Z$ $33 \% 42.5 \mathrm{GHz}$ optical clock signal generated at $1535 \mathrm{~nm}$ by a Mach-Zehnder intensity modulator (MZI) and injected through an optical circulator. The $42.5 \mathrm{GHz}$ optical clock signal generated by the locked FP-MLLD is sent to the programmable optical filters, which are Gaussian and centered at 1549.1, 1552.3, 1555.5 and $1558.8 \mathrm{~nm}$. Each of them delivers a pulse stream with a full width at half maximum between 1.5 and 2 ps according to the channel. Odd and even channels are modulated by two 42.5 Gbit/s 27-1 Pseudo Random Binary Sequences (PRBS) signal thanks two different MZI (MZI1 and MZI2 for odd and even channels respectively). Finally a bit rate multiplier (BRM) multiplexes four delayed versions of the four signals and provides a $4 \times 170$ Gbit/s DWDM/OTDM multiplex. The fiber lengths between each modulator and BRM are sufficiently different to ensure decorrelation of odd and even channels. A standard single mode fiber section is inserted to compensate for the 


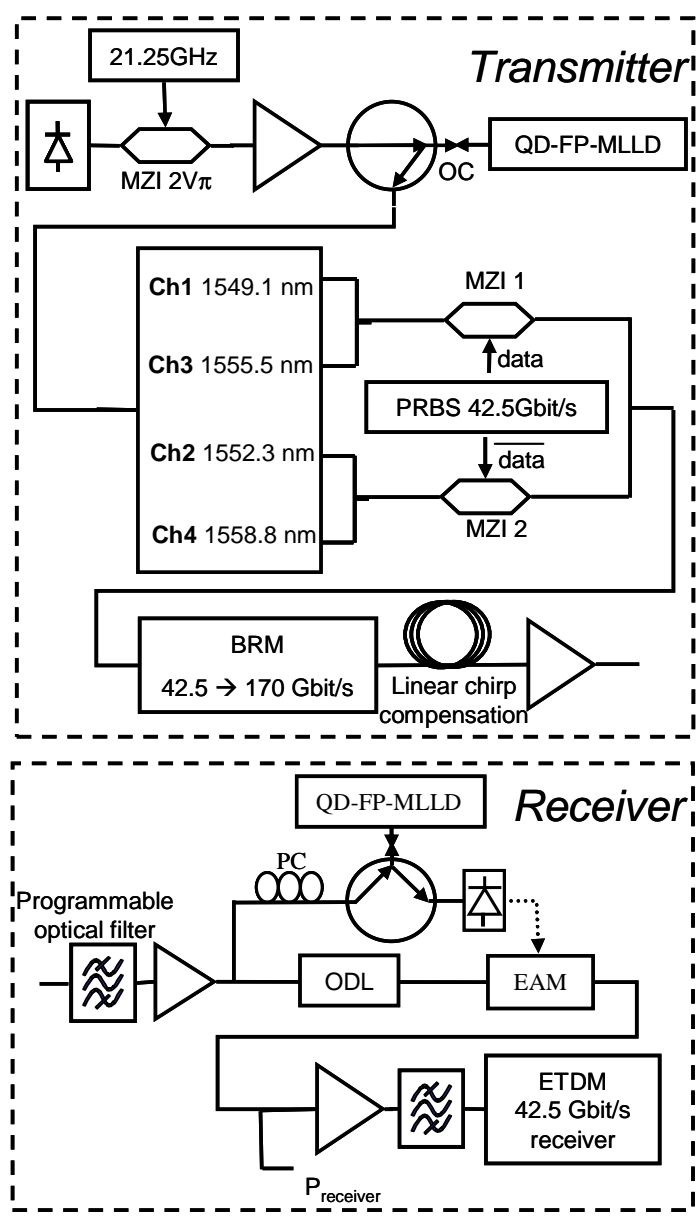

Fig. 2: Experimental setup

residual chirp due to the material dispersion of the laser. The same compensation was used for all channels in all experiments.

The first stage of the receiver block is a programmable optical filter. Its shape and phase can be controlled. This filter selects the channel to be analysed and corrects the second and third order dispersion of the signal before BER analysis. The clock recovery is carried out by a second QD-FP-MLLD ${ }^{4}$. Part of the $170 \mathrm{Gbit} / \mathrm{s}$ signal goes to the laser through an optical circulator and a locked $42.5 \mathrm{GHz}$ optical clock is generated. After detection, this signal pilots an electro-optic absorption modulator (EAM) which provides optical division demultiplexing and extracts one of the four $42.5 \mathrm{Gbit} / \mathrm{s}$ tributaries. An optical delay line (ODL) allows adjusting precisely the demultiplexing. The signal is then optically preamplified and sent to a standard $42.7 \mathrm{Gbit} / \mathrm{s}$ electrical time division demultiplexing (ETDM) receiver for a BER assessment.

Fig. 3 depicts the measured bit error rate (BER) versus the receiver input power for three different cases. For each case, we present the optical spectrum and eye diagram. The first case, called reference, refers to single channel transmission. The second case, called "2 channels", corresponds to the transmission of two channels (odd or even channels). The BER analysis versus receiver input power was performed for channel 2 and 3 (triangles and circles respectively). For this case no penalty was observed compared to the reference case for odd or even channels.

The last case, named " 4 channels", corresponds to the presence of the four channels. A penalty of about $1 \mathrm{~dB}$ can be observed at BER $=10^{-9}$ for channels 2 and 3 . Both channels exhibit a penalty. The eye diagram on the last line in Fig. 3 shows in the case of four channels intensity fluctuations which can be explained by the crosstalk induced by neighbor channels. However, no error floor was observed.

\section{Transmission measurements}

The four channels have been tested in a transmission setup, illustrated in Fig. 4. This setup consists of a $100 \mathrm{~km}$ span of single mode fiber (SMF). The dispersion shifted fiber (DSF) is
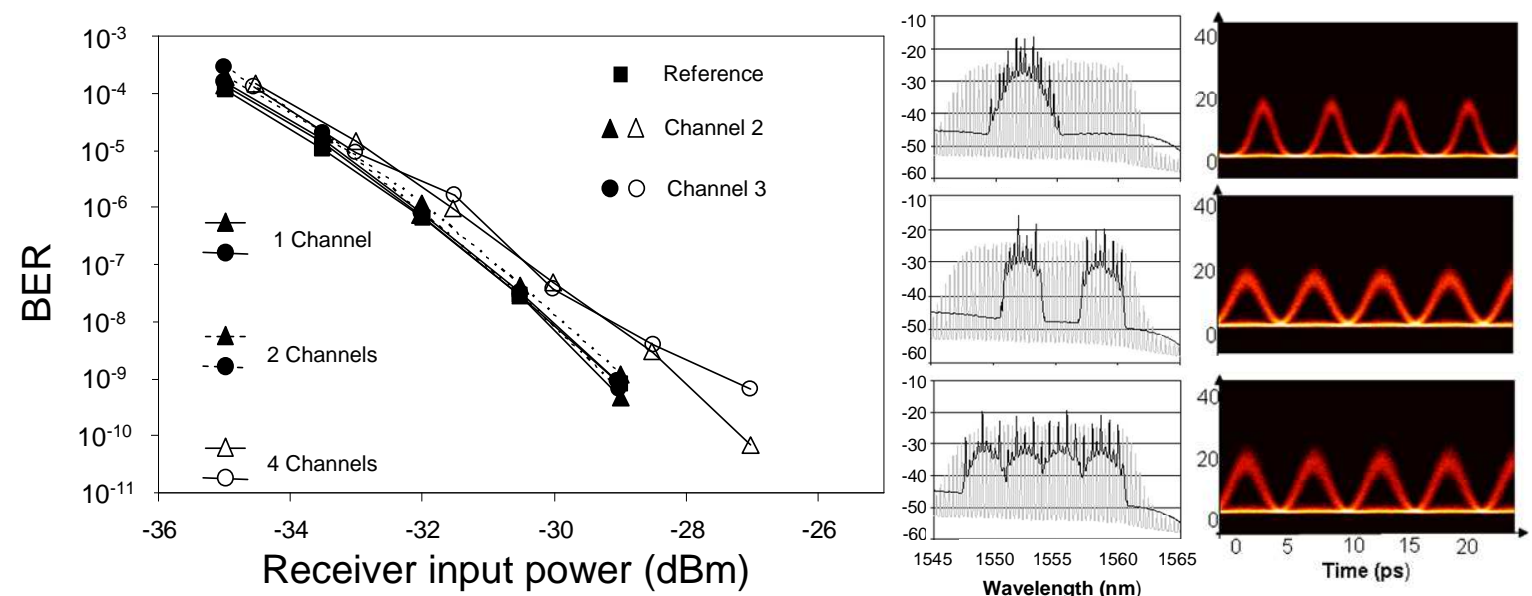

Fig. 3: BER measurements, optical spectrum and eye diagram for back to back for the reference signal, and the presence for 1,2 or 4 channels. The eye diagrams illustrates the channel 2 


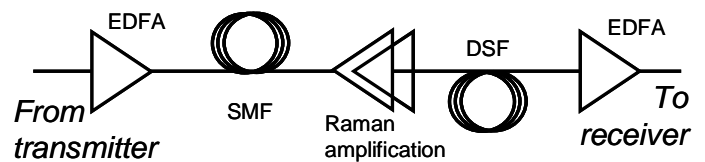

Fig. 4: Transmission setup.

used to dispersion compensation. The losses are compensated by Erbium Doped Fiber Amplifiers (EDFA) and contra-propagative Raman amplification which provides a $15 \mathrm{~dB}$ gain. A booster is used to launch the signal into the fiber, its output power is adjusted to keep for each case a launched power of $3 \mathrm{dBm}$ by channel. The programmable shape optical filter in the receiver is used to adjust the phase profile in order to compensate for the residual chromatic dispersion after transmission.

Fig.5 depicts the bit error rate versus the receiver input power, and the eye diagrams of two $42.5 \mathrm{Gbit} / \mathrm{s}$ tributaries corresponding to channels 2 and 3 before and after the transmission when all channels are present in
DWDM/OTDM transmission using only one Quantum Dash Fabry Perot mode locked laser emitting optical pulses at $42.5 \mathrm{GHz}$. Pulses are shaped by an optical filter leading to short $1.5 \mathrm{ps}$ wide pulses. The presence of four channels induced a penalty of $1 \mathrm{~dB}$ compared to the backto-back experiment. The $4 \times 170$ Gbit/s DWDM/OTDM signal has been transmitted over $100 \mathrm{~km}$ of SMF. An error floor about $10^{-8}$ was observed for a power by channel of $3 \mathrm{dBm}$. The main limitation is cross-talk between the channels. We demonstrate here the compatibility of QD-FP-MLLD with DWDM/OTDM transmission.

\section{Acknowledgement}

We thank Alexandre Shen and Guang-Hua Duan from Alcatel-Thales III-V lab for QD-FPMLLD fabrication.

This work was partly supported by the ANRTelecom project PERSYST II, the French Government, the UE FEDER program, and the Brittany Region.
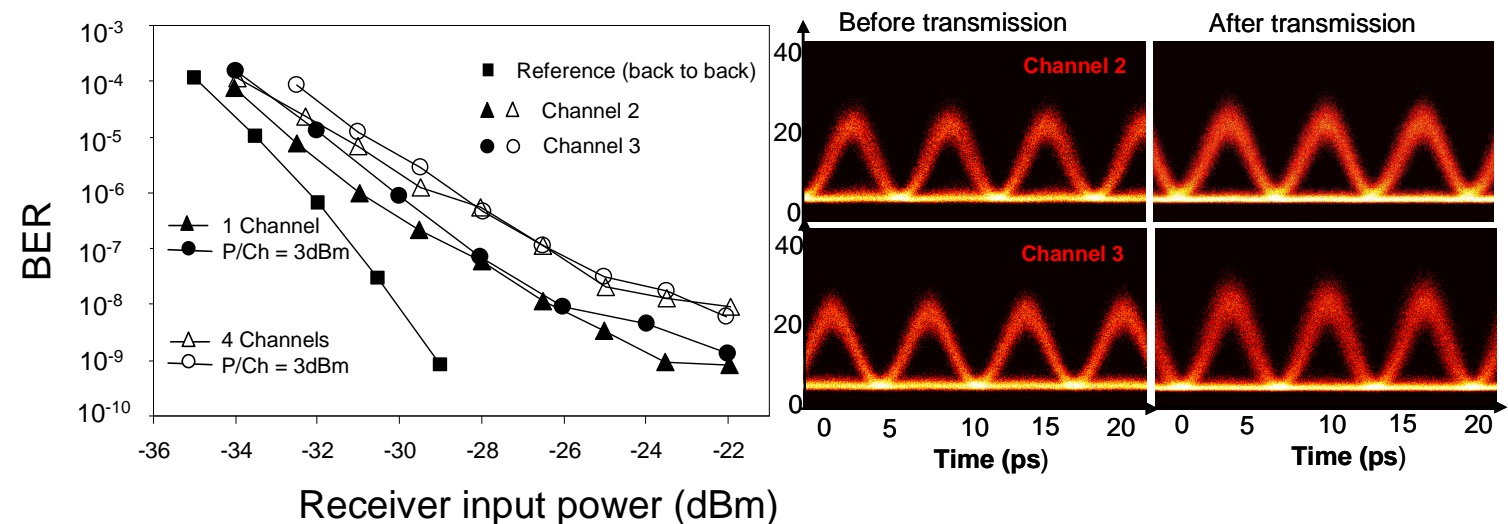

Fig.5: BER measurement and eye diagrams when the 4 channels are transmitted over $100 \mathrm{Km}$.

the system. The reference curve is the same as presented in Fig.3. An error floor is observed for BER roughly equal to $10^{-8}$.

In a single channel configuration (channel 2 or 3 ) with the same launched power per channel, an error floor appears at a BER about $10^{-9}$. These results demonstrate that our WDM transmission is mainly limited by cross-talk between channels.

\section{Conclusions}

We have presented the first $4 \times 170 \mathrm{Gbit} / \mathrm{s}$

\section{References}

$1 \mathrm{~J}$. Renaudier et al, ECOC, PDTh434 (2005).

2 V. Roncin et al, Optics Express, 15, 10 (2007).

$3 \mathrm{~F}$. Lelarge et al, Journal of Selected Topics on

Quantum Electronics, 13, 1, 111 (2007).

$4 \mathrm{M}$. Costa e Silva et al, OFC, PDPC4, (2010)

$5 \mathrm{G}$. Girault et al, Electronics Letters, 44, 14 (2008).

6 A. Shen et al, ECOC, PDTh3D1 (2008).

7 Q.T. Nguyen et al, OFC, OThA3, (2009).

8 M. Costa e Silva et al, ECOC, W622 (2009) 